\title{
Diagnostic performance of the Xpert Carba-R assay for active surveillance of rectal carbapenemase-producing organisms in intensive care unit patients
}

Young Jin Ko ${ }^{1,2^{*}}$ (D), Jeeyong Kim ${ }^{1}$, Ha-Nui Kim', Soo-Young Yoon ${ }^{1}$, Chae Seung Lim ${ }^{1}$ and Chang Kyu Lee ${ }^{1 *}$

\begin{abstract}
Background: There are growing concerns regarding the spread of carbapenemase-producing organisms (CPOs) among patients in long-term care facilities (LTCFs) and hospitals in South Korea. We have established a screening protocol for the detection of CPOs in high-risk patients upon admission to intensive care units (ICUs). The diagnostic performance of the Xpert Carba-R assay was compared to that of rectal culture for CPO detection in high-risk patients upon ICU admission.

Methods: A total of 408 consecutive rectal swabs were obtained from December 2016 to December 2017. CPO screening was performed using the Xpert Carba-R assay (Cepheid, Sunnyvale, CA, USA). When a carbapenemase gene was detected, additional rectal swabs were incubated overnight and inoculated on chromID CARBA medium (bioMérieux, Marcy l'Etoile, France). Bacterial carbapenemase genes, including bla $a_{\mathrm{KPC}}$, bla $a_{\mathrm{NDM}}$, bla $a_{\mathrm{VIM}}$, bla $a_{\mathrm{MP}-1}$, and bla $a_{\text {XX-48, }}$ were confirmed by conventional PCR. The diagnostic performance of the Carba-R assay was ascertained based on the culture results.

Results: The prevalence of CPO carriage was $7.4 \%$ according to the Carba-R assay and $3.7 \%$ according to rectal culture. The median Ct values of IMP-1 and KPC were significantly different (35.2 vs. 26.6, $P=0.0143$ ). The overall sensitivity, specificity, positive predictive value (PPV) and negative predictive value (NPV) of the Carba-R assay were 100.0\% (95\% confidence interval [Cl], 78.2-100.0), 96.7\% (94.4-98.2), 53.6\% (40.4-66.4) and 100.0\% (99.0-100.0), respectively.

Conclusions: We demonstrated the prevalence of CPO carriage in high-risk patients upon ICU admission and evaluated the diagnostic performance of the Carba-R assay. The combined use of the Xpert Carba-R assay and culture produces rapid and reliable results for the active surveillance of rectal CPO in ICU patients.
\end{abstract}

Keywords: Carbapenemase, Surveillance, Xpert Carba-R assay, Gram-negative bacteria, Intensive care unit, Molecular methods, Chromogenic culture

\footnotetext{
* Correspondence: md.seraph@gmail.com; cklee@korea.ac.kr

${ }^{1}$ Department of Laboratory Medicine, Korea University College of Medicine,

126-1, Anam-dong 5-ga, Seongbuk-gu, Seoul 02841, Republic of Korea

Full list of author information is available at the end of the article
}

(c) The Author(s). 2019 Open Access This article is distributed under the terms of the Creative Commons Attribution 4.0 International License (http://creativecommons.org/licenses/by/4.0/), which permits unrestricted use, distribution, and reproduction in any medium, provided you give appropriate credit to the original author(s) and the source, provide a link to the Creative Commons license, and indicate if changes were made. The Creative Commons Public Domain Dedication waiver (http://creativecommons.org/publicdomain/zero/1.0/) applies to the data made available in this article, unless otherwise stated. 


\section{Background}

The global transmission of carbapenem-resistant Enterobacteriaceae (CRE) has accelerated and become a serious public health threat worldwide [1, 2]. Carbapenemase-producing organisms (CPOs) include carbapenemase-producing Enterobacteriaceae (CPE) and carbapenemaseproducing glucose nonfermenting gram-negative bacilli (CP-NF), both of which threaten human health [3]. In Europe, the prevalence of CPE is 1.3 per 10,000 hospital admissions, and the resistance rate of last-resort antibiotics is high [4]. In South Korea, high rates of carbapenem resistance among glucose nonfermenting gram-negative bacilli (CR-NF) and the increased prevalence of CRE have become serious problems in hospitalized patients $[5,6]$. Since November 2010, nationwide sample surveillance has been conducted, and the number of CPE cases reported in South Korea has been dramatically increasing every year [7]. The transmission of CPE and associated outbreaks have become great concerns because of the difficulties associated with their control in both acute care hospitals and long-term care facilities (LTCFs) [6, 8]. Risk factors associated with CPE include intensive care therapy, hospitalization in the previous six months, hospital acquisition and foreign travel in the previous six months [4].

We have established a screening protocol for detecting CPOs in high-risk patients upon admission to intensive care units (ICUs) using real-time PCR and rectal culture (Fig. 1). To pre-emptively isolate CPE-colonized patients, we actively screen for CPOs using the Xpert Carba-R assay (Cepheid, Sunnyvale, CA, USA), which is a rapid and easy-to-use method for detecting five common carbapenemase genes $\left(b l a_{\mathrm{KPC}}, b l a_{\mathrm{NDM}}, b l a_{\mathrm{VIM}}, b l a_{\mathrm{IMP}-1}\right.$, and $\left.b l a_{\text {OXA-48 }}\right)$. In the present study, we aimed to elucidate the prevalence of rectal CPO carriage in high-risk patients admitted to the ICU at a tertiary hospital and to evaluate the performance of this assay for detecting rectal CPOs.

\section{Methods}

\section{Study design}

This study was conducted as a retrospective study. From December 2016 to December 2017, rectal swabs were requested for CPO screening from patients admitted to the ICU at Korea University Medical Center (KUMC), Guro Hospital. Clinical information on the patients was collected from electronic medical records. High-risk patients were defined as patients who had been previously hospitalized in another hospital or LTCF during the three months before admission to KUMC, Guro Hospital, or patients known as CPE carriers.

\section{Evaluation of the limit of detection (LoD)}

Before the study period, we evaluated the LoD of the Xpert Carba- $\mathrm{R}$ assay and culture for carbapenem-resistant organisms (CROs). Five CPO isolates were used to evaluate the carbapenemase genes $b l a_{\mathrm{KPC}}, b l a_{\mathrm{NDM}}$, blaVIM, $b l a_{\text {IMP-1 }}$, and $b l a_{\text {OXA-48. Monobacterial suspensions }}$ of KPC-producing Klebsiella pneumoniae, IMP-1-producing Pseudomonas aeruginosa, NDM-producing Enterobacter aerogenes, VIM-producing $K$. pneumoniae, and OXA-48-producing Escherichia coli in sterile 0.9\% saline were adjusted to a 0.5 McFarland standard. Then, sterile swabs were placed in the inocula subjected to 10 -fold dilutions of $2.25 \times 10^{4}, 2.25 \times 10^{3}, 2.25 \times 10^{2}$ and $2.25 \times$ $10^{1} \mathrm{CFU} / \mathrm{swab}$ and vortexed with the reagent for $10 \mathrm{~s}$. These inocula in $1.7 \mathrm{~mL}$ of reagent solution were transferred into the sample chamber in cartridges. The cartridges were loaded into a GeneXpert IV instrument (Cepheid) according to the manufacturer's instructions. The LoD claimed by the manufacturer was verified as the lowest detected concentration of each of the five CPOs.

To determine the culture LoD, inocula of 10 CPOs were subjected to 10 -fold dilutions of $1 \times 10^{4}, 1 \times 10^{3}$, $1 \times 10^{2}, 1 \times 10^{1}$ and $1 \times 10^{0} \mathrm{CFU} /$ plate and inoculated on chromID CARBA medium (chromID, bioMérieux, Marcy l'Etoile, France); visible colonies were counted after 16,24 , and $48 \mathrm{~h}$ of incubation at $35^{\circ} \mathrm{C}$. These inocula included five KPC-producing organisms ( $K$. pneumoniae, E. coli, K. oxytoca, Citrobacter koseri, and $E$. cloacae), two NDM producers (E. coli and $C$. freundii), one IMP-1-producing $E$. asburiae, one VIMproducing $K$. pneumoniae and one OXA-48-producing E. coli.

\section{CRE culture, susceptibility testing and PCR for carbapenemase genes}

When carbapenemase genes were detected with the Carba-R assay, new rectal swabs were requested for culture during the study period. New swabs were incubated overnight in thioglycolate broth and inoculated into chromID. When the organisms were recovered, identification and antimicrobial susceptibility testing were performed using the Vitek MS (bioMérieux, Manchester, UK) and Vitek 2 (bioMérieux, Hazelwood, MO, USA) instruments. Disk diffusion testing was performed with disks containing $10 \mu \mathrm{g}$ of ertapenem, meropenem and imipenem (Oxoid, Basingstoke, UK) on Muller-Hinton agar. Clinical breakpoints and screening cutoff values for CROs were based on EUCAST breakpoint tables (http://www.eucast.org/fileadmin/src/media/PDFs/ EUCAST_files/Breakpoint_tables/v_9.0_Breakpoint_Tables. pdf).

When CREs were detected, a modified Hodge test and a carbapenemase inhibition test were performed according to the Clinical and Laboratory Standards Institute guidelines and diagnosis guideline for CPE $[9,10]$. Additionally, inhouse PCR for five carbapenemase genes and the Xpert Carba- $R$ assay were performed to confirm the CPOs. 


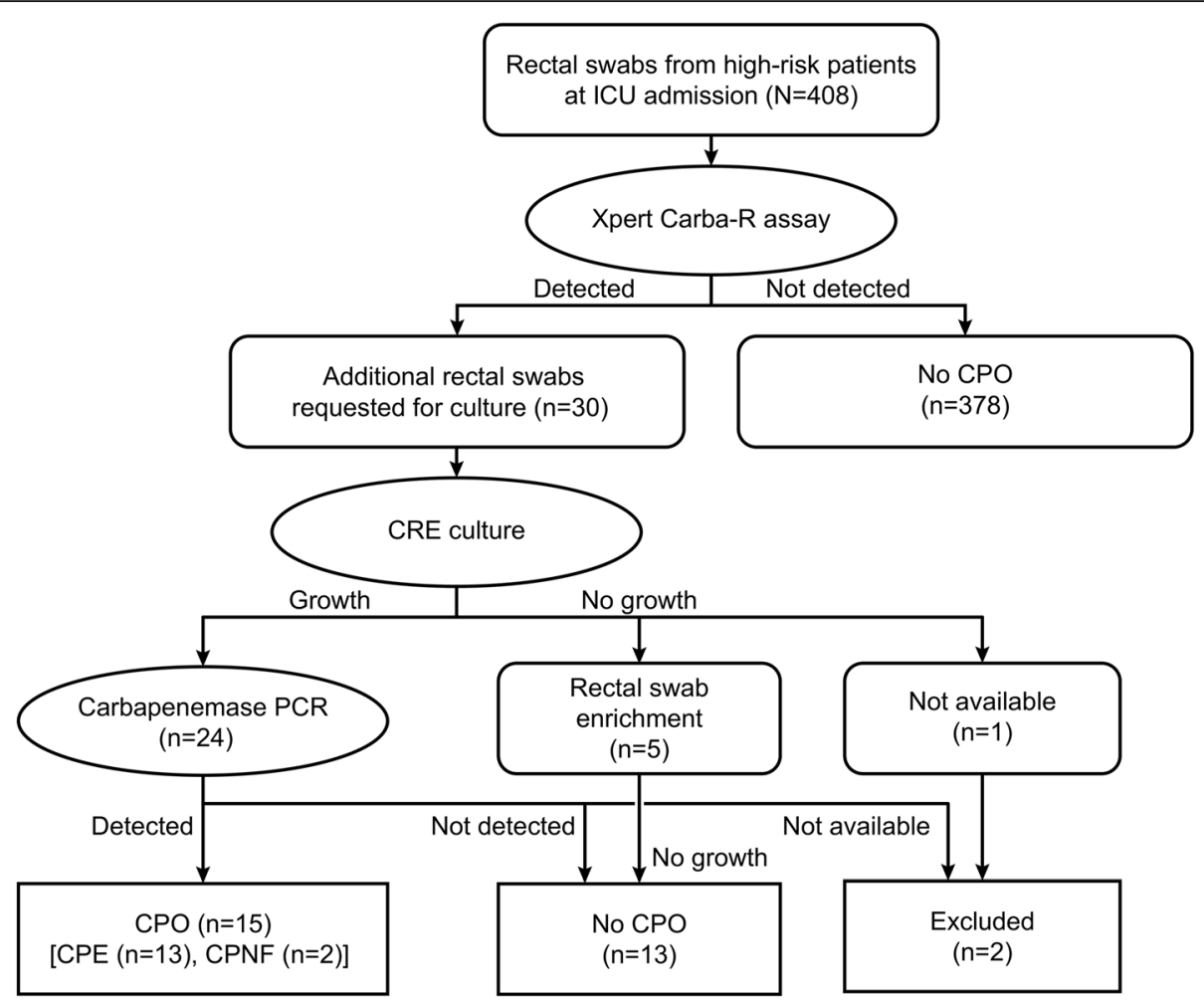

Fig. 1 Screening protocols for carbapenemase-producing organisms in this study

Briefly, bacterial DNA was extracted using a Genedia Mycobacteria DNA Prep Kit (Green Cross Medical Science Corp., Chungbuk, South Korea), and modified multiplex PCR for five carbapenemase genes was performed according to a previous report [11]. After the study period, for the discrepant results between the Carba- $R$ assay and cultures, DNA was extracted from the rectal swabs and sent to a laboratory (Macrogen, Seoul, South Korea) for bidirectional sequencing analysis of the five target genes. The sequencing primers were designed to include the target regions of the Carba- $\mathrm{R}$ assay in the product sequence.

\section{Data analysis and statistics}

Differences in $\mathrm{Ct}$ values between the CPO-recovered and non-CPO-recovered swabs were analyzed using the Mann-Whitney test. The sensitivity, specificity, positive predictive value (PPV) and negative predictive value (NPV) were also calculated. Receiver operating characteristic (ROC) curve analysis and diagnostic performance analysis were performed using MedCalc 14.23 (MedCalc Software, Ostend, Belgium).

\section{Results}

Evaluation of the LoD for the Carba-R assay and CRE culture The highest $\mathrm{Ct}$ values measured for the five CPE isolates were 36.5, 37.7, 32.2, 36.9 and 37.0 for the detection of $b l a_{\mathrm{KPC}}, \quad b l a_{\mathrm{NDM}}, \quad b l a_{\mathrm{VIM}}, \quad b l a_{\mathrm{IMP}-1}$ and $b l a_{\mathrm{OXA}-48}$, respectively, corresponding to 225, 22.5, 2,250, 225 and $225 \mathrm{CFU} /$ swab. Regression analysis generated an equation for the assumed bacterial concentration based on the assigned $\mathrm{Ct}$ values (Fig. 2a). According to the equation, the Carba- $\mathrm{R}$ assay detected $\mathrm{Ct}$ values less than 38.0, corresponding to a bacterial load greater than $46 \mathrm{CFU} /$ swab.

The LoD of chromID for KPC-producing bacteria ranged from 1 to $10 \mathrm{CFU} /$ plate, whereas the LoD for metallo- $\beta$-lactamase (MBL)-producing bacteria ranged from 10 to $100 \mathrm{CFU} /$ plate. The LoD of chromID for OXA-48-producing bacteria was $1 \times 10^{4} \mathrm{CFU} /$ plate (Table 1).

\section{Prevalence of rectal CPO carriage}

A total of 408 rectal swabs were analyzed during the study period. The prevalence of rectal CPO carriage upon admission to the ICU was 7.4\% (30 of 408) and $3.7 \%$ (15 of 406) among high-risk patients according to the Carba- $\mathrm{R}$ assay and culture results, respectively. IMP$1(13,3.2 \%)$ and KPC (10, 2.5\%) were predominantly detected by the Carba-R assay, followed by $\operatorname{NDM}(4,1.0 \%)$, VIM (0.2\%), KPC with OXA-48 (0.2\%) and KPC with IMP-1 (0.2\%) (Table 2).

Seventeen CPO strains were recovered from newly collected 29 rectal swabs. Twelve KPC-producing organisms were recovered from 11 KPC-positive 

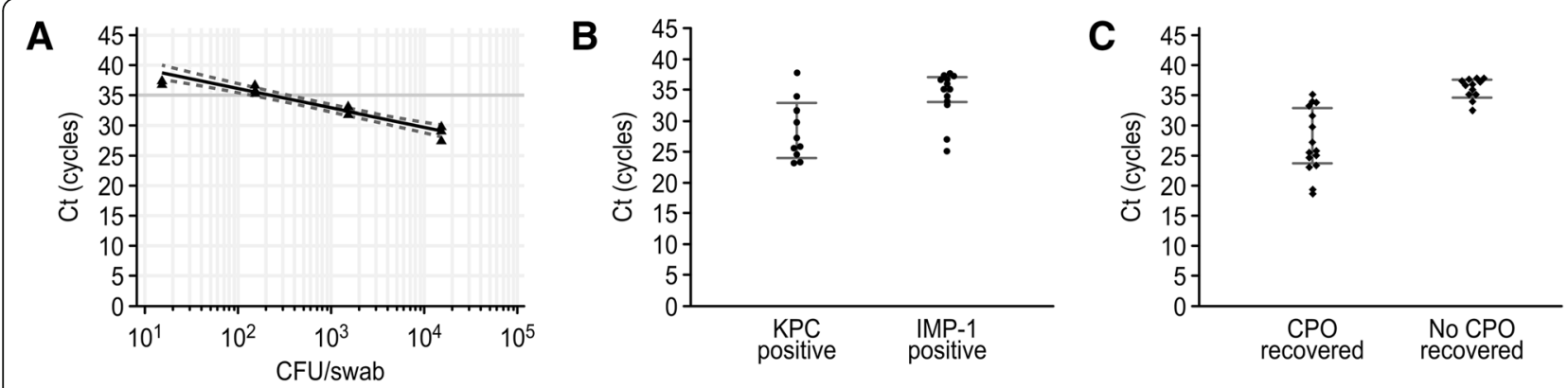

Fig. 2 LoD of the Carba-R assay and comparison of the Ct values combined with CRE cultures. Regression analysis of the Ct values from the Carba-R assay corresponding to bacterial concentrations of $10^{4}, 10^{3}, 10^{2}$ and $10^{1} \mathrm{CFU} / \mathrm{swab}$ (a). The gray line indicates a Ct value of $35 \mathrm{cycles}$. Comparison of the Ct values from KPC-positive and IMP-1-positive rectal swabs (b). Comparison of the Ct values from rectal swabs with and without CPO recovery $(\mathbf{c})$

rectal swabs, including $7 K$. pneumoniae strains, four E. coli strains, and one C. koseri strain. One KPCproducing $K$. pneumoniae and one KPC-producing $E$. coli strain were recovered from KPC-negative/other gene-positive rectal swabs. Among the four NDMpositive rectal swabs, one NDM-producing $K$. pneumoniae strain was recovered. For most IMP-1-positive rectal swabs, the recovered bacteria were not CPOs, except two IMP-1-producing $P$. aeruginosa strains. VIM- or OXA-48-producing organisms were not recovered during the study period (Table 2). KPC producers $(12,3.0 \%)$ were predominantly recovered, followed by IMP- 1 producers $(2,0.5 \%)$ and NDM producer $(1$, $0.2 \%)$.

\section{Diagnostic performance of the Carba-R assay}

In the Carba- $\mathrm{R}$ assay, $\mathrm{Ct}$ values higher than 35.0 for rectal swabs corresponded to bacterial concentrations of less than $390 \mathrm{CFU} / \mathrm{swab}$, and most of these swabs did not produce CRE culture growth during the study period (Fig. 2). The median $\mathrm{Ct}$ values of the Carba- $\mathrm{R}$ assay were significantly different between $\mathrm{KPC}$ - and IMP-1-producing organisms (26.6 vs. 35.2, $P=0.0143$ ) (Fig. 2b). Additionally, the median $\mathrm{Ct}$ values of the assay were significantly different between rectal swabs containing $\mathrm{CPOs}$ and non-CPO rectal swabs (25.9 vs. 36.7, $P=0.0001$ ) (Fig. 2c).

The overall sensitivity, specificity, PPV and NPV were 100.0, 96.7, 53.6, and 100.0\%, respectively, when the Ct value recommended by the manufacturer $(38.0$ cycles) was applied as the cutoff (Table 3). Because of the differences in prevalence among carbapenemase genes, the diagnostic performance varied according to the type of carbapenemase gene detected. Due to the small number of detected organisms, the diagnostic performance of VIM and OXA48 in terms of sensitivity and PPV could not be calculated.

Table 1 The detection limit of CRE culture stratified by carbapenemase genes

\begin{tabular}{|c|c|c|c|c|c|}
\hline \multirow[t]{2}{*}{ Carbapenemases } & \multirow[t]{2}{*}{ Strains } & \multicolumn{3}{|c|}{ Disk diffusion (mm) } & \multirow{2}{*}{$\begin{array}{l}\text { The lowest detection limit of } \\
\text { CRE culture (CFU/plate) }\end{array}$} \\
\hline & & Ertapenem & Imipenem & Meropenem & \\
\hline \multicolumn{6}{|c|}{ Ambler class A carbapenemase } \\
\hline KPC & C. koseri 150 & 15 & 18 & 18 & 1 \\
\hline KPC & E. cloacae 207 & 7 & 19 & 15 & 10 \\
\hline KPC & K. oxytoca 211 & 18 & 22 & 23 & 1 \\
\hline KPC & K. pneumoniae 222 & 11 & 17 & 13 & 1 \\
\hline KPC & E. coli 223 & 15 & 17 & 20 & 1 \\
\hline \multicolumn{6}{|c|}{ MBL carbapenemase } \\
\hline NDM & C. freundii 148 & 18 & 20 & 19 & 100 \\
\hline NDM & E. coli 192 & 6 & 12 & 10 & 10 \\
\hline VIM & K. pneumoniae 225 & 18 & 19 & 19 & 10 \\
\hline IMP-1 & E. asburiae 44 & 16 & 21 & 19 & 100 \\
\hline \multicolumn{6}{|c|}{ Ambler class D carbapenemase } \\
\hline OXA-48 & E. coli 229 & 19 & 22 & 23 & $1 \times 10^{4}$ \\
\hline
\end{tabular}


Table 2 Distribution of carbapenemase genes detected by the Xpert Carba-R assay and the recovered carbapenemase-producing organisms

\begin{tabular}{|c|c|c|c|c|c|}
\hline \multirow{2}{*}{ 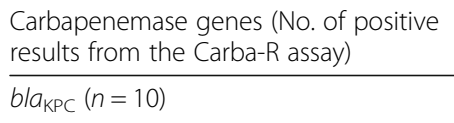 } & \multirow{2}{*}{$\begin{array}{l}\text { Recovered strains from } \\
\text { additional rectal culture } \\
\text { Klebsiella pneumoniae }\end{array}$} & \multicolumn{2}{|c|}{$\begin{array}{l}\text { PCR confirmation } \\
\text { of the CPO strains }\end{array}$} & \multirow{2}{*}{$\begin{array}{l}\text { No. of patients } \\
5\end{array}$} & \multirow{2}{*}{$\begin{array}{l}\text { No. of CPO strains } \\
5\end{array}$} \\
\hline & & $\mathrm{KPC}$ & CPE & & \\
\hline & Escherichia coli & $\mathrm{KPC}$ & CPE & 2 & 2 \\
\hline & $\begin{array}{l}\text { Klebsiella pneumoniae } \\
\text { Escherichia coli }\end{array}$ & $\begin{array}{l}\mathrm{KPC} \\
\mathrm{KPC}\end{array}$ & CPE & 1 & 2 \\
\hline & No growth & No growth & No CPO & 1 & 0 \\
\hline & Not available & NA & NA & 1 & 0 \\
\hline bla $a_{\mathrm{KPC}}, b a_{\mid \mathrm{MP}-1}(n=1)$ & $\begin{array}{l}\text { Escherichia coli } \\
\text { Citrobacter koseri }\end{array}$ & $\begin{array}{l}\mathrm{KPC} \\
\mathrm{KPC}\end{array}$ & CPE & 1 & 2 \\
\hline bla $_{\mathrm{KPC},}$ bla $\mathrm{OXA}-48(n=1)$ & $\begin{array}{l}\text { Klebsiella pneumoniae } \\
\text { Pseudomonas aeruginosa }\end{array}$ & $\begin{array}{l}\text { KPC } \\
\text { Negative }\end{array}$ & CPE & 1 & 1 \\
\hline \multirow[t]{4}{*}{$b^{b} a_{N D M}(n=4)$} & Escherichia coli & $\mathrm{KPC}$ & CPE & 1 & 1 \\
\hline & Klebsiella pneumoniae & NDM & CPE & 1 & 1 \\
\hline & Pseudomonas aeruginosa & Negative & No CPO & 1 & 0 \\
\hline & Klebsiella pneumoniae & Negative & No CPO & 1 & 0 \\
\hline bla $_{\mathrm{VIM}}(n=1)$ & $\begin{array}{l}\text { Klebsiella pneumoniae } \\
\text { Escherichia coli }\end{array}$ & $\begin{array}{l}\text { KPC } \\
\text { Negative }\end{array}$ & CPE & 1 & 1 \\
\hline \multirow[t]{5}{*}{$b a_{\mid \mathrm{MP}-1}(n=13)$} & Pseudomonas aeruginosa & IMP-1 & CP-NF & 2 & 2 \\
\hline & Acinetobacter baumannii & Negative & No CPO & 4 & 0 \\
\hline & Pseudomonas aeruginosa & Negative & No CPO & 2 & 0 \\
\hline & Pseudomonas aeruginosa & NA & NA & 1 & 0 \\
\hline & No growth & No growth & No CPO & 4 & 0 \\
\hline
\end{tabular}

Abbreviations: CPO carbapenemase-producing organism, CPE carbapenemase-producing Enterobacteriaceae, $C P$-NF carbapenemase-producing glucose nonfermenting gram-negative bacilli, NA not available

The overall specificity and PPV were improved in the ROC curve analysis when a diagnostic cutoff value of 35.0 cycles was applied (Table 4 ). The areas under the ROC curve (AUCs) were not significantly different in a pairwise comparison of ROC curves when 38.0 and 35.0 cycles were used as cutoff values $(0.98$ vs. 0.96 , $P=0.5405)$. Using a cutoff value of 35.0 cycles, the overall specificity/PPV improved from $96.7 \% / 53.6 \%$ to $99.2 \% / 82.4 \%$, with minimal differences in the AUC.

\section{Discussion}

We actively screened for rectal CPOs to support the pre-emptive isolation of ICU patients, with the results showing that the prevalence of rectal CPOs in high-risk patients using the Carba- $\mathrm{R}$ assay was similar to that of a previous report in South Korea [5]. The prevalence of rectal $\mathrm{CPO}$ carriage varied by region and was observed in $0.1 \%$ of UK hospitals in 2015 and $19.2 \%$ of Spanish hospitals in 2017 [12, 13]. The distribution of carbapenemase

Table 3 Diagnostic performance of the Carba-R assay stratified by carbapenemase gene

\begin{tabular}{|c|c|c|c|c|c|c|c|c|c|c|}
\hline \multirow{2}{*}{$\begin{array}{l}\text { Carbapenemase gene (No. of } \\
\text { carbapenemase genes detected } \\
\text { by the Carba-R assay) }\end{array}$} & \multirow[t]{2}{*}{$\begin{array}{l}\text { CPO carriage } \\
\text { by culture (\%) }\end{array}$} & \multicolumn{5}{|c|}{$\begin{array}{l}\text { No. of specimens with } \\
\text { the following results }\end{array}$} & \multicolumn{4}{|c|}{$\%$ (95\% confidence interval) } \\
\hline & & Total & $\mathrm{TP}$ & $\mathrm{FP}$ & $\mathrm{TN}^{*}$ & FN & Sensitivity & Specificity & PPV & NPV \\
\hline $\mathrm{KPC}(n=11)^{* *}+$ & 3.0 & 406 & 10 & 1 & 393 & 2 & $83.3(51.6-97.9)$ & $99.8(98.6-100.0)$ & $90.9(58.2-98.6)$ & $99.5(98.2-99.9)$ \\
\hline $\operatorname{NDM}(n=4)$ & 0.2 & 406 & 1 & 3 & 402 & 0 & $100.0(2.5-100.0)$ & $99.3(97.9-99.8)$ & $21.3(8.1-45.5)$ & $100.0(99.1-100.0)$ \\
\hline $\operatorname{VIM}(n=1)$ & NA & 406 & 0 & 1 & 405 & 0 & NA & $99.8(98.6-100.0)$ & NA & $100.0(99.1-100.0)$ \\
\hline $\operatorname{IMP}-1(n=13)^{* *} \dagger$ & 0.5 & 406 & 2 & 11 & 393 & 0 & $100.0(15.8-100.0)$ & $97.3(95.2-98.6)$ & $15.6(9.3-24.8)$ & $100.0(99.1-100.0)$ \\
\hline OXA-48 $(n=1)^{* *}$ & NA & 406 & 0 & 1 & 405 & 0 & NA & $99.8(98.6-100.0)$ & NA & $100.0(99.1-100.0)$ \\
\hline Total $(n=28)$ & 3.7 & 406 & 15 & 13 & 378 & 0 & $100.0(78.2-100.0)$ & 96.7 (94.4-98.2) & $53.6(40.4-66.4)$ & $100.0(99.0-100.0)$ \\
\hline
\end{tabular}

* Specimens not detected by the Carba- $R$ assay were considered as true negative results

**Two specimens were detected as KPC + IMP-1 and KPC + OXA-48

TThe other two specimens were excluded because the results of PCR or CRE culture were not available.

Abbreviations: $C P O$ carbapenemase-producing organism, $T P$ true positive, $F P$ false positive, $T N$ true negative, $F N$ false negative, $P P V$ positive predictive value, NPV negative predictive value 
Table 4 ROC curve analysis of the Carba-R assay stratified by carbapenemase gene and the cutoff Ct value

\begin{tabular}{|c|c|c|c|c|c|c|}
\hline \multirow{2}{*}{$\begin{array}{l}\text { Carbapenemase } \\
\text { gene }\end{array}$} & \multirow{2}{*}{$\begin{array}{l}\text { Cutoff } \mathrm{Ct} \\
\text { value (cycles) }\end{array}$} & \multicolumn{4}{|c|}{$\%$ (95\% confidence interval) } & \multirow[t]{2}{*}{ AUC } \\
\hline & & Sensitivity & Specificity & PPV & NPV & \\
\hline \multirow[t]{2}{*}{ KPC } & $\leq 38.0$ & $83.3(51.6-97.9)$ & $99.8(98.6-100.0)$ & $90.9(58.7-99.8)$ & $99.5(98.2-99.9)$ & $0.92(0.88-0.94)^{*}$ \\
\hline & $\leq 35.0$ & $83.3(51.6-97.9)$ & $100.0(99.1-100.0)$ & $100.0(69.2-100.0)$ & $99.5(98.2-99.9)$ & $0.92(0.89-0.94)^{*}$ \\
\hline \multirow[t]{2}{*}{ IMP-1 } & $\leq 38.0$ & $100.0(15.8-100.0)$ & $97.5(95.5-98.8)$ & $16.7(2.1-48.4)$ & $100.0(99.1-100.0)$ & $0.99(0.97-1.00)^{*}$ \\
\hline & $\leq 35.0$ & $50.0(1.3-98.7)$ & $99.3(97.8-99.8)$ & $25.0(0.6-80.6)$ & $99.8(98.6-100.0)$ & $0.75(0.70-0.79)$ \\
\hline \multirow[t]{2}{*}{ Total } & $\leq 38.0$ & $100.0(78.2-100.0)$ & $96.7(94.4-98.2)$ & $53.6(33.9-72.5)$ & $100.0(99.0-100.0)$ & $0.98(0.97-0.99)^{*}$ \\
\hline & $\leq 35.0$ & $93.33(68.1-99.8)$ & $99.2(97.8-99.8)$ & $82.4(56.6-96.2)$ & $99.7(98.6-100.0)$ & $0.96(0.94-0.98)^{*}$ \\
\hline
\end{tabular}

${ }^{*} P<0.0001$, Abbreviations: PPV positive predictive value, NPV negative predictive value, AUC area under the ROC curve

also exhibited regional variance. In Romania, Spain, and Turkey, OXA-48 was most frequently detected among $K$. pneumoniae, while KPC was the most detected carbapenemase in South Korea, Greece, Italy, and Portugal $[4,6]$.

The $\mathrm{Ct}$ values of the Carba- $\mathrm{R}$ assay in this study could predict $\mathrm{CPO}$ recovery in culture. The cutoff $\mathrm{Ct}$ value was previously reported to distinguish false-positive or insignificant results from true CPO results [14]. The cutoff value for CPO recovery in this study was 35.0 cycles, which corresponded to a bacterial concentration of 390 $\mathrm{CFU} / \mathrm{swab}$. The concentration of bla $_{\mathrm{IMP}-1}$ in most specimens was assumed to be less than $390 \mathrm{CFU} / \mathrm{swab}$ in this study. However, the sensitivity of IMP-1 decreased from 100.0 to $50.0 \%$ when using the adjusted cutoff value (35.0), which resulted from the recovery of one IMP-1 positive specimen with a $\mathrm{Ct}$ value of 35.1. Therefore, further studies are needed since there was an insufficient number of recovered IMP-1 producers to determine the recovery cutoff.

The type of carbapenemase gene may affect the CPO recovery of chromID CARBA medium (chromID). Our LoD values for chromID ranged from 1 to $10 \mathrm{CFU} /$ plate for KPC producers, 10 to $100 \mathrm{CFU} /$ plate for MBL carbapenemase producers, and the LoD for OXA-48 producers was $1 \times 10^{4} \mathrm{CFU} /$ plate. These results are consistent with a previous report in which the LoD for $\mathrm{KPC}$-producing bacteria was $1 \times 10^{1} \mathrm{CFU} /$ plate, with values of $1 \times 10^{1}$ to $1 \times 10^{6} \mathrm{CFU} /$ plate for NDM- and VIM-producing bacteria and $1 \times 10^{5} \mathrm{CFU} /$ plate for OXA-48-producing bacteria [15]. ChromID is known to be insufficient for detecting OXA-48-producing bacteria because of its low analytic sensitivity [14]. However, we did not use ChromID OXA-48 medium during the study period due to the low incidence of OXA-48-producing strains in our hospital.

We frequently detected the $b l a_{\mathrm{IMP}-1}$ gene in this study, with a detection rate of $3.2 \%$; however, most of the isolated bacteria did not contain this gene. Only two strains of IMP-1-producing $P$. aeruginosa were recovered from 13 IMP-1-positive rectal swabs. $P$. aeruginosa is usually present at lower concentrations than other gram-negative bacteria in the perianal region [16]. Therefore, a low concentration of $P$. aeruginosa can be considered a major cause of inconsistency with culture results. The Carba-R assay can detect the IMP-1, IMP-3, IMP-6, IMP-10, IMP-25, and IMP-30 subgroups without distinction. Notably, IMP-6-producing $P$. aeruginosa has become a predominant clone, and IMP-10-producing $P$. aeruginosa has recently emerged in South Korea $[17,18]$. In addition, most of the carbapenemase-producing $P$. aeruginosa isolates were previously observed to exhibit extensive drug resistance and showed susceptibility only to colistin in 2015 [18].

We found four NDM-positive cases, from which only one NDM-producing bacterial strain was cultured. To address this discrepancy, three NDM- and three IMP-1-positive/culture-negative specimens were collected, and direct PCR sequencing of the five carbapenemase genes was performed. We detected $b l a_{\text {NDM }}$ sequences in one NDMpositive swab, from which meropenem-susceptible $K$. pneumoniae was recovered. This isolate showed weak positivity in the Hodge test, resistance to ertapenem, and susceptibility to imipenem. We also found a $b a_{\text {IMP-1 }}$ sequence in one IMP-1-positive swab from which bacteria were not recovered. This sequence showed 99.1\% homology with $b l a_{\mathrm{IMP}-1}, b l a_{\mathrm{IMP}-14}, b l a_{\mathrm{IMP}-48}$ and $b l a_{\mathrm{IMP}-54}$. No other carbapenemase gene sequences were found in the other specimens. In summary, the low concentration of CPOs in rectal swabs, the false-positive results obtained for NDM and IMP-1 using the Carba-R assay and the weak hydrolysis of MBL carbapenemase were the primary causes of discordance between the Carba- $R$ assay and culture results in this study.

Most studies have validated and evaluated the Carba- $R$ assay using contrived specimens of $b l a_{\mathrm{IMP}-1}$ producers or pure colonies [19-22]. All five types of carbapenemase genes, including $b l a_{\text {IMP-1 }}$, were detected with a low prevalence in this study. In addition, the clinical performance of the Carba- $\mathrm{R}$ assay using rectal swabs for active surveillance was reliable and concordant with that of a previous report, except for the PPV of the $b l a_{\text {IMP-1 }}$ and $b l a_{\mathrm{NDM}}$ genes $[19,20]$. The combined use of the Carba- $\mathrm{R}$ assay and culture was found to be a sensitive and specific screening method for CPOs [22]. This 
combination is advantageous because the molecular method detects only the target gene and allows falsepositive results, whereas rectal culture can identify which bacteria are carbapenem-resistant but may be less sensitive because of the abundance of other enteric bacteria [23]. The Carba- $R$ assay enables the detection of most carbapenemase genes, including the recently emerging $b l a_{\mathrm{OXA}-181}$ and $b l a_{\mathrm{OXA}-232}$ genes; however, $b l a_{\mathrm{GES}}$ cannot be detected by the assay [24]. Thus, regional epidemiology should be considered when choosing a screening method for $\mathrm{CPO}$ detection [22].

To prevent CPO transmission, all ICU patients were pre-emptively isolated on the day of admission and subsequently released from quarantine according to the Carba$\mathrm{R}$ assay result, which was reported daily. For the patients who tested positive by the Carba- $\mathrm{R}$ assay, the quarantine was released after three consecutive negative CRE culture results. This protocol shortened the period of unnecessary patient isolation and reduced medical staff fatigue.

This study has several limitations. We compared the results of the Carba-R assay and CRE cultures for carbapenemase gene-positive specimens. The Carba- $R$ assay was an imperfect reference method which had the possibility of false negativity, especially for a $b l a_{\text {KPC }}$ gene. After the study period, we compared the Carba-R assay and CRE culture results for 100 PCR-negative specimens. CRE was not cultured for any of the PCR-negative specimens. Among the specimens, five strains of carbapenem-susceptible $P$. aeruginosa and one strain of carbapenem-resistant A. baumannii complex were recovered. No carbapenemase gene was detected in the strain. The Carba- $\mathrm{R}$ assay of prospectively collected rectal swabs from the previous study also did not have a false-negative result [23].

The Carba-R assay did not detect $b l a_{\mathrm{GES}}$, and we could not exclude the presence of $b l a_{\mathrm{GES}}$ in this study. However, regarding the local epidemiology near the hospital, bla $a_{\mathrm{GES}}$ and other carbapenemase genes have not been reported [7]. The low prevalence of bla $a_{\mathrm{VIM}}$ and $b l a_{\text {OXA- } 48}$ limited the calculation of the sensitivity and PPV in this study. Further large-scale studies directly comparing culture combined with direct PCR-sequencing and the Carba-R assay for $\mathrm{CPO}$ detection will elucidate these limitations.

\section{Conclusions}

We demonstrated the prevalence of rectal CPO carriage in high-risk patients upon admission to the ICU in a tertiary hospital and evaluated the diagnostic performance of the Xpert Carba- $R$ assay. The combined use of the Xpert Carba- $\mathrm{R}$ assay and culture produces rapid and reliable results for active surveillance of rectal $\mathrm{CPO}$ in ICU patients. The use of cutoff $\mathrm{Ct}$ values to improve the specificity of the Xpert Carba-R assay was applicable for decision-making associated with patient isolation.

\section{Abbreviations}

AST: Antimicrobial susceptibility test; AUC: Area under the ROC curve;

CFU: Colony forming unit; CPE: Carbapenemase-producing Enterobacteriaceae; CP-NF: Carbapenemase-producing glucose nonfermenting gram-negative bacilli; CPO: Carbapenemase-producing organism; CR-NF: Carbapenem-resistant glucose nonfermenting gram-negative bacilli; CRO: Carbapenem-resistant organism; Ct: threshold cycle; EUCAST: The European Committee on Antimicrobial Susceptibility Testing; FN: False negative; FP: False positive; ICU: Intensive care unit; IMP: Imipenemase; KPC: Klebsiella pneumoniae carbapenemase; LTCF: Long-term care facility; MBL: Metallo- $\beta$-lactamase; NA: Not available; NDM: New Delhi metallo-ß-lactamase; NPV: Negative predictive value; OXA: Oxacillinase; PPV: Positive predictive value; ROC: Receiver operating characteristic; TN: True negative; TP: True positive; VIM: Verona integron-encoded metallo- $\beta$-lactamase

\section{Acknowledgements}

This study was presented in part at the 28th European Congress of Clinical Microbiology and Infectious Diseases (ECCMID) in Madrid, Spain, on 21-24 April 2018.

\section{Authors' contributions}

YJK devised the study and wrote the manuscript in consultation with CKL. JK and HNK analyzed and interpreted the data. SYY and CSL helped carry out the experiments. All authors provided critical feedback and helped shape the research. All authors read and approved the final manuscript.

\section{Funding}

This study was supported by a grant from Korea University Medical Center, Guro Hospital (O1801451)

\section{Availability of data and materials}

Not applicable.

\section{Ethics approval and consent to participate}

This study was approved by the Institutional Review Board (IRB) of the Korea University Medical Center, Guro Hospital (2018GR0191). The medical records used in this study had been obtained previously as part of routine medical procedures. As the data in this study were collected and analyzed retrospectively, the study did not infringe upon the rights or welfare of the patients and did not require consent.

\section{Consent for publication}

Not applicable.

\section{Competing interests}

The authors declare that they have no competing interests.

\section{Author details}

${ }^{1}$ Department of Laboratory Medicine, Korea University College of Medicine, 126-1, Anam-dong 5-ga, Seongbuk-gu, Seoul 02841, Republic of Korea. ${ }^{2}$ Present address: Department of Laboratory Medicine, Chosun University Hospital, Gwangju, Republic of Korea.

Received: 4 April 2019 Accepted: 16 July 2019

Published online: 29 July 2019

References

1. Albiger B, Glasner C, Struelens MJ, Grundmann H, Monnet DL. Carbapenemase-producing Enterobacteriaceae in Europe: assessment by national experts from 38 countries, may 2015. Euro Surveill. 2015;20:1-18.

2. Logan LK, Weinstein RA. The epidemiology of carbapenem-resistant Enterobacteriaceae: the impact and evolution of a global menace. J Infect Dis. 2017;215:S28-36.

3. Gniadek TJ, Carroll KC, Simner PJ. Carbapenem-resistant non-glucosefermenting gram-negative bacilli: the missing piece to the puzzle. J Clin Microbiol. 2016:54:1700-10.

4. Grundmann H, Glasner C, Albiger B, Aanensen DM, Tomlinson CT, Andrasevic AT, et al. Occurrence of carbapenemase-producing Klebsiella pneumoniae and Escherichia coli in the European survey of carbapenemaseproducing Enterobacteriaceae (EUSCAPE): a prospective, multinational study. Lancet Infect Dis. 2017;17:153-63. 
5. Kim DK, Kim HS, Pinto N, Jeon J, D'Souza R, Kim MS, et al. Xpert Carba$\mathrm{R}$ assay for the detection of carbapenemase-producing organisms in intensive care unit patients of a Korean tertiary care hospital. Ann Lab Med. 2016:36:162-5.

6. Kim YA, Park YS. Epidemiology and treatment of antimicrobial resistant gram-negative bacteria in Korea. Korean J Intern Med. 2018;33:247-55

7. Yoon EJ, Yang JW, Kim JO, Lee H, Lee KJ, Jeong SH. Carbapenemaseproducing Enterobacteriaceae in South Korea: a report from the national laboratory surveillance system. Future Microbiol. 2018;13:771-83.

8. Lin MY, Lyles-Banks RD, Lolans K, Hines DW, Spear JB, Petrak R, et al. The importance of long-term acute care hospitals in the regional epidemiology of Klebsiella pneumoniae carbapenemase-producing Enterobacteriaceae. Clin Infect Dis. 2013;57:1246-52.

9. Clinical and Laboratory Standards Institute (CLSI). Performance standards for antimicrobial susceptibility testing; twenty-seventh informational supplement. CLSI document M100-S27. 27th ed. Wayne, PA: Clinical and Laboratory Standards Institute; 2017.

10. Song W, Hong SG, Yong D, Jeong SH, Kim HS, Kim HS, et al. Combined use of the modified Hodge test and carbapenemase inhibition test for detection of carbapenemase-producing Enterobacteriaceae and metallo-beta-lactamase-producing pseudomonas spp. Ann Lab Med. 2015;35(2):212-9.

11. Poirel L, Walsh TR, Cuvillier V, Nordmann P. Multiplex PCR for detection of acquired carbapenemase genes. Diagn Microbiol Infect Dis. 2011;70:119-23.

12. Simner PJ, Martin I, Opene B, Tamma PD, Carroll KC, Milstone AM Evaluation of multiple methods for detection of gastrointestinal colonization of carbapenem-resistant organisms from rectal swabs. J Clin Microbiol. 2016:54:1664-7.

13. García-Castillo M, Reilly M, Pérez-Viso B, Ruiz-Garbajosa P, Moreno R. Evaluation of the BD MAX check-points CPO assay for rapid detection of carbapenemase-producing organisms in rectal swab specimens from highrisk wards [abstract]. In: the European Congress of Clinical Microbiology and Infectious Diseases 18 ${ }^{\text {th }}$. Madrid: Spain; April 2018. p. 21-4.

14. Lau AF, Fahle GA, Kemp MA, Jassem AN, Dekker JP, Frank KM. Clinical performance of check-direct CPE, a multiplex PCR for direct detection of bla $a_{\mathrm{KPC}}, b / a_{\mathrm{NDM}}$ and/or bla $a_{\mathrm{VIM}}$ and bla $a_{\mathrm{OXA}-48}$ from perirectal swabs. J Clin Microbiol. 2015:53:3729-37.

15. Girlich D, Anglade C, Zambardi G, Nordmann P. Comparative evaluation of a novel chromogenic medium (chromID OXA-48) for detection of OXA-48 producing Enterobacteriaceae. Diagn Microbiol Infect Dis. 2013:77:296-300.

16. Warnke P, Pohl FJP, Kundt G, Podbielski A. Screening for gram-negative bacteria: impact of preanalytical parameters. Sci Rep. 2016;6:30427.

17. Yoo JS, Yang JW, Kim HM, Byeon J, Kim HS, Yoo Jl, et al. Dissemination of genetically related IMP-6-producing multidrugresistant Pseudomonas aeruginosa ST235 in South Korea. Int J Antimicrob Agents. 2012;39:300-4.

18. Hong JS, Yoon E-J, Lee H, Jeong S, Lee K. Clonal dissemination of Pseudomonas aeruginosa sequence type 235 isolates carrying blalMP-6 and emergence of blaGES-24 and blaIMP-10 on novel genomic islands PAGI-15 and-16 in South Korea. Antimicrob Agents Chemother. 2016;60:7216-23.

19. Tato M, Ruiz-Garbajosa P, Traczewski M, Dodgson A, McEwan A, Humphries $R$, et al. Multisite evaluation of Cepheid Xpert Carba-R assay for detection of carbapenemase-producing organisms in rectal swabs. J Clin Microbiol. 2016:54:1814-9.

20. Moore NM, Canton R, Carretto E, Peterson LR, Sautter RL, Traczewski MM, et al. Rapid identification of five classes of Carbapenem resistance genes directly from rectal swabs by use of the Xpert Carba-R assay. J Clin Microbiol. 2017;55(7):2268-75

21. Tenover FC, Canton R, Kop J, Chan R, Ryan J, Weir F, et al. Detection of colonization by carbapenemase-producing gram-negative bacilli in patients by use of the Xpert MDRO assay. J Clin Microbiol. 2013:51:3780-7.

22. Traczewski MM, Carretto E, Canton R, Moore NM. Multicenter evaluation of the Xpert Carba-R assay for detection of carbapenemase genes in gram-negative isolates. J Clin Microbiol. 2018;56:e00272-18.

23. Miller SA, Hindler JA, Chengcuenca A, Humphries RM. Use of ancillary Carbapenemase tests to improve specificity of phenotypic definitions for
Carbapenemase-producing Enterobacteriaceae. J Clin Microbiol. 2017:55(6):1827-36.

24. Hoyos-Mallecot $Y$, Ouzani S, Dortet L, Fortineau N, Naas T. Performance of the Xpert((R)) Carba-R v2 in the daily workflow of a hygiene unit in a country with a low prevalence of carbapenemase-producing Enterobacteriaceae. Int J Antimicrob Agents. 2017;49:774-7.

\section{Publisher's Note}

Springer Nature remains neutral with regard to jurisdictional claims in published maps and institutional affiliations.

\section{Ready to submit your research? Choose BMC and benefit from:}

- fast, convenient online submission

- thorough peer review by experienced researchers in your field

- rapid publication on acceptance

- support for research data, including large and complex data types

- gold Open Access which fosters wider collaboration and increased citations

- maximum visibility for your research: over $100 \mathrm{M}$ website views per year

At BMC, research is always in progress.

Learn more biomedcentral.com/submissions 